\title{
Commentary \\ Evidence-based guidelines for bleeding in trauma patients: where do we go from here?
}

Joseph P Minei

Department of Surgery, UT Southwestern Medical Center and Parkland Memorial Hospital, Dallas, Texas, USA

Correspondence: Joseph P Minei, joseph.minei@utsouthwestern.edu

Published: 27 April 2007

This article is online at http://ccforum.com/content/11/2/128

(c) 2007 BioMed Central Ltd

See related research by Spahn et al., http://ccforum.com/content/11/1/R17
Critical Care 2007, 11:128 (doi:10.1186/cc5737)

\begin{abstract}
The development of evidence-based guidelines has gained popularity as a strategy to reduce variation in practice and to orient clinical care around documentable best practices. Based on available data, the new European guidelines for the management of bleeding in the trauma patient do deliver a number of sound recommendations. However, some issues remain controversial and, like many guidelines, the actual translation of these evidencebased recommendations into routine clinical practice protocols continues to leave opportunity for variation. Nevertheless, this consensus guideline provides an excellent starting point. As evidence continues to accumulate, future iterations should provide greater specificity and move us closer to the definitive best practice.
\end{abstract}

The European guidelines for the management of bleeding in the trauma patient recently reported by Spahn and coworkers [1] is a multidisciplinary, multi-institutional, evidence-based, consensus-driven approach to the diagnosis and management of bleeding in the injured patient. It is well referenced, well written, and timely in nature. Although potentially susceptible to bias introduced by the authors, the grading system used is generally appropriate. The majority of the recommendations are sound and are centered around rapid control of surgical bleeding, proper resuscitation, and transfusion of red cells and coagulation factors.

Fittingly, the authors make their most important recommendation first; 'The time between injury and definitive control of bleeding must be minimized.' Although seemingly obvious, in a recent study from a high-volume, mature trauma system, a common cause of preventable death was failure to identify and control surgical bleeding [2]. Therefore, this initial recommendation cannot be stressed enough.

However, some of the other recommendations - based on less definitive data - remain controversial and are not necessarily mainstream. Also, some of the recommendations need to be placed in context, particularly in terms of the dynamic continuum of patient management over time. For example, the recommendation that red cell transfusion be based on a conservative transfusion trigger (hemoglobin 7 to $9 \mathrm{~g} / \mathrm{dl}$ ) is based on solid evidence. However, that evidence applies only to the stabilized (postoperative) patient who is no longer bleeding massively. Within this context it would be unwise to await laboratory data to decide whether to transfuse an acutely bleeding patient. Under such dynamic circumstances, the decision must be based on clinical factors such as vital signs, response to resuscitation, volume of ongoing bleeding, and the success of surgical attempts to control bleeding. Likewise, transfusion of thawed plasma under those circumstances should not await the results of an international normalized ratio (INR, for prothrombin time), but rather the decision should be based on clinical factors. Once bleeding is controlled and the patient is stabilized, such strict laboratory-guided transfusion practices can be followed.

In fact, recent evidence indicates that coagulation products should be infused very early, indeed pre-emptively, in the face of ongoing severe hemorrhage. In an attempt to minimize the coagulopathy associated with severe bleeding and transfusion, protocols for massive transfusion have been developed by a number of institutions $[3,4]$ as well as the US military in Iraq [5]. Although the optimal ratio of blood to plasma transfusion is yet to be determined definitively, recent data suggest that this ratio is probably close to $1: 1$ in the patient with massive bleeding and shock. If they are eventually demonstrated to be effective, such early infusions of plasma would be given long before hemoglobin and INR tests could be performed.

Regardless of these types of caveats, converting evidencebased recommendations into standard day-to-day operational procedures can still leave plenty of opportunity for interpretation and resulting variability in practice. For example, 
recommendation 4 from the bleeding management guideline states that, 'We recommend that patients presenting with haemorrhagic shock and an identified source of bleeding undergo an immediate bleeding control procedure unless initial resuscitation measures are successful.' For the purposes of an operational protocol, how does one define 'successful resuscitation'? A definition of successful resuscitation to one surgeon may still be considered a state of ongoing bleeding and continued need for transfusion by another.

At the heart of this matter is the presumption that, ultimately, there is a "best way" to care for bleeding patients. The goal of evidence-based guidelines is to help develop recommendations not only to identify the best practice but also to decrease variability in delivery of care. However, while more definitive data are lacking, many guidelines - including many of those in the present discussion - must remain fairly broad in order to accommodate controversial and divergent points of view. Accordingly, the European guideline should be viewed as an excellent and timely consensus, but one that will remain a work-in-progress that must continually be refined as new data are accumulated.

The authors should be applauded for their tremendous initiative; moreover, it is strongly recommended that they continue to regroup regularly in order to refine these recommendations further as permitted by the evolving evidence.

\section{Competing interests}

The author declares that they have no competing interests.

\section{References}

1. Spahn DR, Cerny V, Coats TJ, Duranteau J, Fernandez-Mondejar E, Gordini G, Stahel PF, Hunt BJ, Komadina R, Neugebauer E, et al.: Management of bleeding following major trauma: a European guideline. Crit Care 2007,11:R17.

2. Gruen RL, Jurkovich GJ, Mclntyre LK, Foy HM, Maier RV: Patterns of errors contributing to trauma mortality: lessons learned from 2.594 deaths. Ann Surg 2006, 244:371-380.

3. Gonzalez EA, Moore FA, Holcomb JB, Miller CC, Kozar RA, Todd SR, Cocanour CS, Balldin BC, McKinley BA: Fresh frozen plasma should be given earlier to patients requiring massive transfusion. J Trauma 2007, 62:112-119.

4. Malone DL, Hess JR, Fingerhut A: Massive transfusion protocols around the globe and a suggestion for a common massive transfusion protocol. J Trauma 2006, Suppl 6:S91S96.

5. Holcomb JB, Jenkins $\mathrm{D}$, Rhee $\mathrm{P}$, Johannigman J, Mahoney $\mathrm{P}$, Mehta S, Cox ED, Gehrke MJ, Beilman GJ, Schreiber M, et al:: Damage control resuscitation: directly addressing the early coagulopathy of trauma. J Trauma 2007, 62:307-310. 